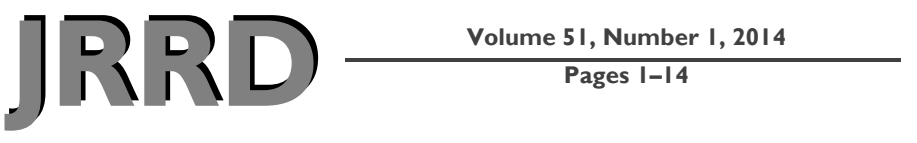

\title{
Considerations for development of sensing and monitoring tools to facilitate treatment and care of persons with lower-limb loss: A review
}

\author{
Brian J. Hafner, $\mathbf{P h D} ;^{1}$ Joan E. Sanders, $\mathbf{P h D}^{\mathbf{2}^{*}}$ \\ Departments of ${ }^{1}$ Rehabilitation Medicine and ${ }^{2}$ Bioengineering, University of Washington, Seattle, WA
}

\begin{abstract}
Sensing and monitoring technologies offer enormous potential to enhance the quality of healthcare provided to persons with lower-limb loss. Incorporation of these technologies into the rehabilitation process creates opportunities for a multidimensional exchange of timely, relevant, and meaningful health information between patients, their prostheses, and healthcare providers. Here, the authors envision a conceptual model for enhancing prosthetic rehabilitation through use of integrated physical and/or biological sensors and remote monitoring methods. Several specific applications that target treatment, diagnosis, and prognosis of health issues faced by persons with limb loss are proposed in an effort to demonstrate how collecting and using objective data can facilitate clinical decision making. Contemporary integrated sensors that may be used in these applications are reviewed and their limitations discussed. It is hoped that the considerations proposed here may serve to stimulate development of clinically useful monitoring and sensing technologies and promote their integration into routine amputation rehabilitation.
\end{abstract}

Key words: ambulatory monitoring, amputee, diagnosis, limb loss, outcome assessment, prognosis, prosthesis, remote sensing technology, therapy/treatment, wireless sensors.

\section{BACKGROUND}

Recent estimates suggest that more than 1.75 million people living in the United States have experienced limb loss, primarily resulting from dysvascular disease, trauma, or cancer [1]. Moreover, the prevalence of limb loss is expected to more than double (to 3.6 million people in the United States) over the next four decades as the population ages and the expected increases in adverse health conditions such as obesity, diabetes, and dysvascular disease manifest [1-3]. Although digit (i.e., finger or toe) amputations comprise a majority of these estimates, approximately 42 percent of these cases are considered to be "major" limb amputations that occur in more proximal areas of the body. Furthermore, most (i.e., more than 90\%) major limb loss occurs in the lower limb proximal to the toes [1]. Given the critical role that the lower limb plays in balance, transfers, and ambulation, it is not unexpected that severe physical impairment in the lower limb significantly decreases an individual's ability to function at home and in the community [2-4].

Recovery from major limb loss is a lifelong, personal struggle that requires the attention and experience of a multidisciplinary clinical team of physicians, therapists, and prosthetists [5]. Rehabilitation following an amputation commonly includes the prescription of a prosthetic limb in an effort to address patients' specific functional, vocational, and recreational needs. However, even with the use of a prosthesis, persons with lower-limb loss face a lifetime of functional limitations and continual health threats, including decreased balance [6-10]; increased metabolic energy expenditure while walking [11-13];

\footnotetext{
*Address all correspondence to Joan E. Sanders, PhD; Department of Bioengineering, University of Washington, Box 355061, William H. Foege Bldg, 3720 15th Ave NE, Seattle, WA 98195; 206-221-5872; fax: 206-616-2509. Email: jsanders@u.washington.edu http://dx.doi.org/10.1682/JRRD.2013.01.0024
} 
decreased walking speed [12,14-15]; gait asymmetries [14,16-17]; increased frequency of stumbles and falls [9,18]; reduced activity level [19-21]; difficulty negotiating uneven terrain, hills, and stairs [5,22-24]; skin breakdown [25-27]; joint degeneration [28-30]; and pain [3134]. These issues collectively contribute to a significantly reduced health-related quality of life [25,35-38] among individuals with lower-limb loss when compared with individuals without amputation [39-40]. From a healthcare system perspective, the postamputation rehabilitation process is also time-consuming [4] and expensive [41]. Therefore, strategies and/or tools to facilitate the treatment and lifelong management of limb loss are needed to address the medical needs of this rapidly growing patient population.

Postamputation rehabilitation is intended to address patients' functional needs through therapeutic (e.g., gait training) and prosthetic (e.g., specific components) interventions as well as to mitigate medical conditions (e.g., skin breakdown) that threaten patients' long-term welfare. The selection of appropriate and timely rehabilitative interventions traditionally relies upon the experience of the clinician with input from the patient. This "experience-based" approach to amputee care may be visualized as a one-dimensional exchange of information between the practitioner and patient during regularly scheduled clinical visits (Figure 1). The information obtained may include the patient's physical presentation, results of administered clinical tests, and/or subjective responses to posed questions. These insights enable the practitioner to assess a patient's status, observe longitudinal changes, and make treatment recommendations. These data are often collected retrospectively, infrequently (i.e., during

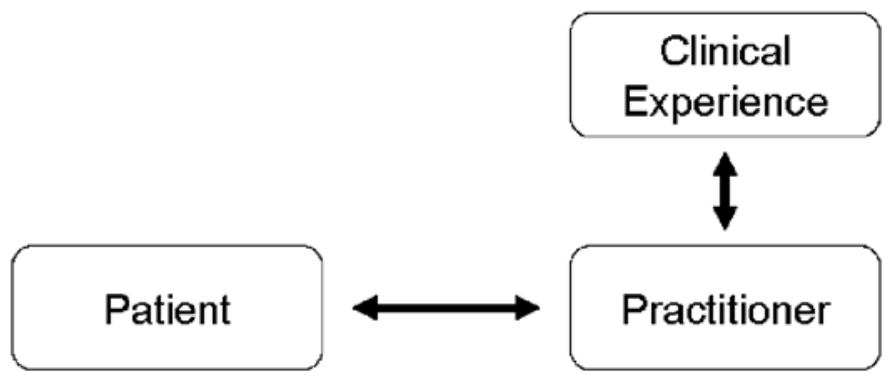

Figure 1.

Traditional model of amputee rehabilitation, where experience informs clinical decisions and is augmented by information obtained from patient. scheduled visits), and in a controlled clinic environment that may not well reflect real-world conditions (i.e., a patient's free-living environment). Experience-based care is also predicated on patient self-report and, as such, may be affected by limitations inherent in subjective survey instruments, such as generalization, comprehension, perception, honesty, and recall [42-46]. These concerns may be pronounced among persons with limb loss who experience cognitive impairments due to diabetes [47] or peripheral arterial disease [48]. Ultimately, these compounding issues may precipitate a reactionary and iterative approach to amputee care that is inefficient, timeconsuming, and expensive.

An extension of experienced-based care (as described previously) is an evidence-based approach, where a practitioner develops a treatment plan through the use of both sound clinical experience and best available empirical evidence (Figure 2) [49]. The intervention is then applied and clinical outcomes are later evaluated and revised, as necessary, using feedback from the patient. Although this form of healthcare considers objective data (in the form of published research) in the derivation of the treatment plan, retrospective clinical assessment using traditional, in-clinic outcome measures [50] is still subject to those same limitations (i.e., subjectivity, infrequency of assessment opportunities, and compromised

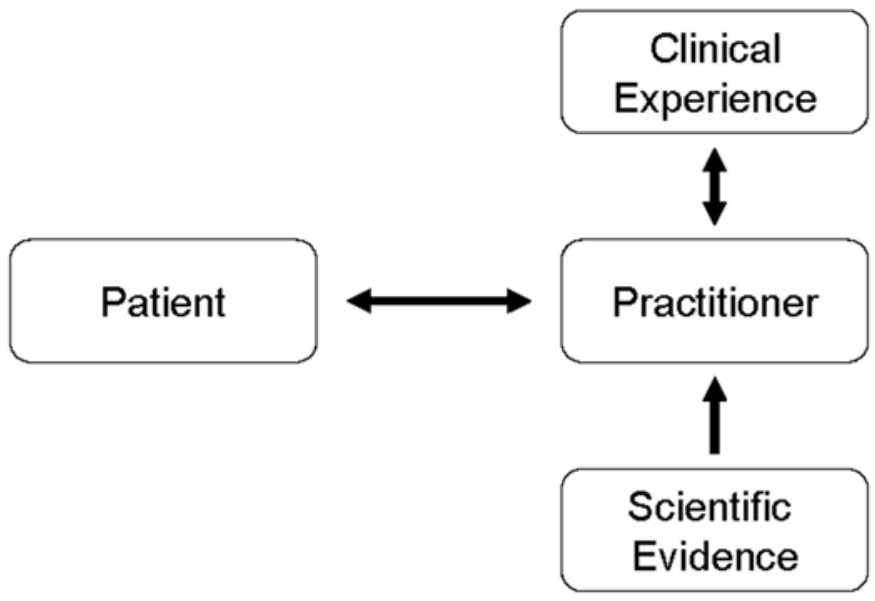

Figure 2.

Evidence-based model of amputee rehabilitation, where both scientific evidence and clinical experience are incorporated into clinical decision-making process, augmented by information obtained from patient. 
cognitive status of patients) present in the aforementioned experience-based approach.

Limitations to these contemporary experience- and evidence-based models of care could potentially be addressed through direct and objective assessment of patients' outcomes throughout the rehabilitation process. Sensing and monitoring technologies have the potential to affect patient care by providing practitioners with the ability to monitor a patient's status, progress, and outcomes more frequently and could enable them to make more informed (and timely) decisions based on meaningful, objective data. The collected patient-specific information could then be used to help prescribe, change, and/ or justify therapies and interventions and better ensure patients are receiving optimal care for their specific needs. Data obtained using sensing and monitoring technologies would complement clinician expertise and existing empirical evidence, thereby enhancing the overall quality of care provided to patients. Further, evidence obtained in this manner could be used to more efficiently and effectively allocate appropriate resources to a growing population of people facing acute physical limitations and medical issues.

The purpose of this article is to review existing solutions for collecting and using objective data to support and/or facilitate clinical decisions related to prosthetic rehabilitation as well as to suggest new strategies for applying this information in routine clinical practice. It is believed that the use of novel solutions for the purposes of restoring and optimizing function following limb loss will promote healthier lifestyles, improve quality of life, and decrease individuals' reliance upon physical, personal, and financial assistance.

\section{EXISTING STRATEGIES AND TECHNOLOGIES}

Periodic (e.g., pre- and postintervention) assessment of clinical outcomes is standard practice in most rehabilitation settings. However, continuous or perpetual assessment of outcomes in other settings (e.g., at home or in the community) is far less common. Advances in sensing and remote monitoring technologies have encouraged adoption of modern telemedicine solutions in wellness applications (e.g., weight loss and physical activity) and chronic conditions (e.g., diabetes, asthma, and heart failure) [51-54]. This form of healthcare offers a variety of potential benefits, including reduced numbers of clinical visits, reduced numbers of hospitalizations, reduced medical costs, and increased quality of life [55-57]. However, to date, application of remote monitoring technologies for the purposes of evaluating functional outcomes in areas such as amputee rehabilitation or prosthetic management has received little attention.

Conceptually, the use of remote monitoring technologies may be better suited to measuring functional outcomes in persons with limb loss than nondisabled users. Existing sensing devices are typically worn on the wrist, waist (i.e., belt), ankle, or other bodily location [58]. On nondisabled users, placement of the device in these locations often necessitates that the user remove and replace the device for activities such as bathing or sleeping. Nondisabled users may also selectively discontinue wear of a sensing device for aesthetic reasons (e.g., going out in public or formal dress occasions). As such, adherence to a regular protocol of removal and reapplication is needed to obtain useful, perpetual data.

For persons with limb loss, a prosthesis provides an ideal vehicle for sensing technologies, particularly for purposes such as ambulatory monitoring. Because a prosthesis is typically removed for sleeping and bathing, attaching sensors to or integrating them within a prosthesis seems to be a logical means to overcome the aforementioned compliance limitations to remote sensing identified in nondisabled users, especially because the modest addition of weight required for such devices would not appear to affect movement or energy expenditure [59-61].

Efforts to obtain and provide practitioners with information about prosthetic patients' activity in their freeliving environments have resulted in the development of several different monitoring devices, only some of which are intended to be attached directly to a prosthesis. These existing products may be loosely grouped under two categories (i.e., accelerometer-based and strain-gage-based), depending on the device's inherent sensing technology.

Accelerometer-based devices have been used to approximate activity through measurement of step counts [62-65]. Data collected with accelerometer-based devices is collected perpetually, stored locally (i.e., on the unit), and then retrieved later. Numerous accelerometer-based activity monitors have been described in the literature [66]. Accelerometer-based devices require low power and accurately measure steps across a range of walking speeds. However, commercial step-monitoring devices developed to date have limitations. Step counts 
provide limited clinical information as to how the prosthesis is used or how activities affect the user. Thus, prosthetic interventions (such as shock-absorbing pylons or microprocessor-controlled prosthetic knees) that are designed to alter loading patterns, demonstrate no clinical effect when step counts are used as an outcome [67-68]. Further, because step monitors are sensitive, stand-alone devices, they must be properly oriented on the patient to collect accurate data. Failure to wear the device properly results in incomplete or erroneous information.

Recent advances in low-power sensor technologies and signal processing techniques have enabled researchers to overcome the aforementioned limitations and also to expand the capabilities of accelerometer-based devices to measure a variety of postural positions (e.g., sitting, standing, lying down) and physical activities (e.g., walking, sit-to-stand transitions) [69]. Modern accelerometers are now sufficiently sensitive to be used as inclinometers (e.g., to measure the angle of the pylon relative to vertical) [70]. Angulation data are proving clinically useful to help distinguish sitting, standing, walking, and doffing, facilitating characterization of amputee activity outside the clinic [71].

Strain-gage-based devices that are attached directly to the prosthesis have been developed to measure prosthetic pylon forces and moments [72-76]. Pylon force and moment data may provide information about gait abnormalities, prosthesis misalignment, or improper componentry that put the prosthesis user at risk of falling or other injury. Strain-gage devices require more power than accelerometer devices, but provide additional information (i.e., up to three forces and three moments) regarding how the prosthesis is loaded. Given the power required to operate strain-gage-based devices, they are used to collect data perpetually only when tethered to a power supply or run on batteries for short-term intervals (e.g., up to 7 h [iPecs Lab, College Park Industries; Fraser, Michigan]). Hence, strain-gage-based prosthetic sensors have been limited to short-term use in research settings [67-71]. Other limitations with specific straingage technologies may include relatively low and poor resolution (i.e., low bandwidth), crosstalk, and long-term fatigue. These issues may limit a sensor's ability to pick up high-frequency events, measure with accuracy, and/or operate reliably over extended periods of time.

For monitoring outside the laboratory for long-term intervals, other sensing technologies, such as piezoelectric sensors (e.g., triaxial ICP force sensor [PCB Piezo- tronics Inc; Depew, New York]) or limb-socket interface pressure sensors (e.g., Pliance [Novel; St. Paul, Minnesota]) require less power and thus may be capable of longer monitoring intervals. A number of research devices have been developed to monitor shear stress at interfaces [77-84], but none are commercially available.

Although the motivations for collecting perpetual, clinically relevant information in free-living environments using existing technologies (e.g., accelerometers, load cells) are sound, current solutions are limited in their ability to accurately and efficiently measure characteristics of clinical interest to a physical rehabilitation team (e.g., types and frequencies of activities performed, gait abnormalities that might identify imminent injury). Further, existing tools often require that the practitioner learn to use complex, customized software to retrieve and interpret the data collected by the device(s). Existing solutions do not align with the needs of an efficient practice and instead often add to the overall time and expense of care provided. Efforts need to be pursued to develop comprehensive, efficient solutions with simple, yet useful, user interfaces that allow practitioners (and/or patients) to quickly and easily retrieve and interpret information of clinical interest.

\section{NEW PARADIGM AND POTENTIAL APPLICATIONS}

To address the need for objective information to support and facilitate the rehabilitation of persons with lower-limb loss, efforts should target the development of systems that interface with and disseminate information from existing and emerging remote monitoring technologies. Such systems would include, at a minimum, a sensing component, a notification strategy, and management software. The sensing unit would obtain critical, objective information directly from the device (i.e., the prosthesis) prescribed to a patient. The notification strategy would make data available to the practitioner and patient at desired intervals. The management software would allow the practitioner and user to customize how and when the data are collected and made available. Integration of such systems into clinical practice would allow for a multidimensional, bidirectional exchange of information among the patient, the practitioner, and/or the device (Figure 3). 


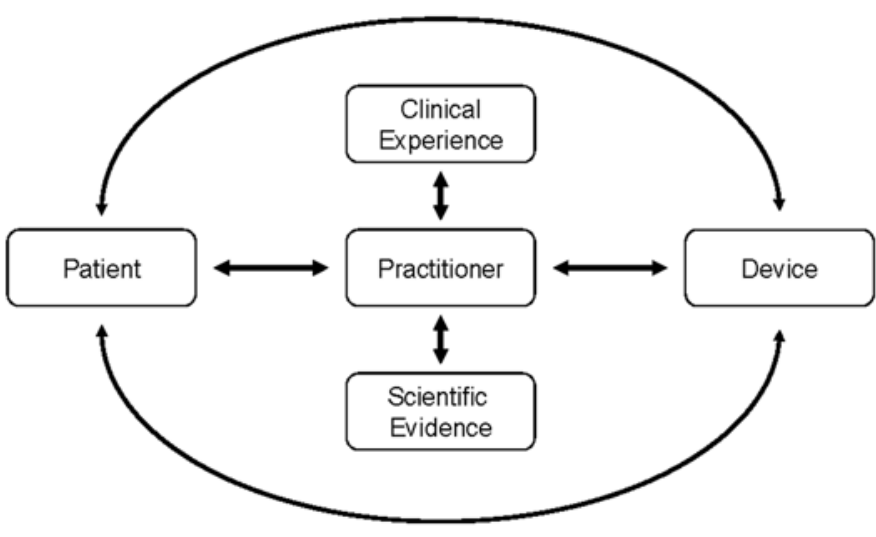

Figure 3.

Multidimensional model of amputee rehabilitation, where information is obtained from and exchanged between patient, sensing device, and practitioner. This model allows for practitioners to use objective information to make informed clinical decisions as well as potentially contribute data to growing body of scientific evidence.

A solution such as that presented here represents a paradigm shift in limb loss healthcare and offers advantages over current approaches to prosthetic rehabilitation that are based only on experience or evidence from the scientific literature. First, the practitioner can access the device to obtain knowledge of a patient's historical or present status in his or her free-living environment and community, thereby augmenting the patient-reported experience with valid and reliable data that is unencumbered with the limitations of subjective recall. Second, patients can access the device to evaluate their performance against practitioner-established goals for a personalized and interactive rehabilitation program. Engaging patients in this way is a strategy that has been recognized to improve physical activity [85] and is likely to benefit many aspects of amputee rehabilitation. Lastly, the device can monitor user performance for indications of adverse events, such as stumbles, suspension failure, or imminent skin breakdown and notify the practitioner and/ or patient of unsafe behaviors. Ultimately, use of this system would be expected to better inform individualized treatment strategies and to help establish objective rationale for the prescription of specific prosthetic components intended to optimize a patient's function, health, safety, and quality of life.

The clinical applications for such a system are diverse. Here, we illustrate how one type of sensing tech- nology (i.e., load or force sensors) could be applied to address clinical issues that span the traditional domains of evidence-based medicine (i.e., therapy/treatment, diagnosis, and prognosis). Load sensors were selected because of our familiarity with their features, limitations, and potential. However, other sensing technologies (e.g., other physical or biological sensors) could be similarly configured to address routine challenges encountered by members of the prosthetic rehabilitation team (i.e., the physician, therapist, prosthetist, and/or patient). It is hoped that these examples may stimulate discussion, development, and use of these and other sensors in prosthetic monitoring applications.

\section{Therapy/Treatment}

One application for the proposed sensing system is as a therapeutic monitor. A therapeutic monitor is used to facilitate and measure outcomes achieved through use of prescribed prosthetic interventions. When configured for such purposes, the sensing unit is temporarily or permanently integrated into the patient's prosthesis (depending on the desired length of observation) and measures important clinical outcomes, such as activity, residuallimb loads, or daily use of the prosthesis. Once the sensor is affixed to or integrated into the prosthesis, the practitioner works with the patient to establish meaningful and realistic rehabilitation targets for the outcomes of interest. The management software is then configured to record the patient's daily, weekly, and/or monthly outcomes. The notification system uploads the desired data to a server and presents it with respect to established targets using a Web-based graphical user interface. The notification frequency can be easily adjusted to suit the needs of the practitioner and/or patient. For example, the patient may desire daily updates on his or her progress, while the practitioner may only solicit summary reports during the patient's regular office visits in order to establish future rehabilitation goals. Ideally, a scalable notification system like this will allow for the desired information to be made efficiently available to both parties.

As a conceptual example of this application, consider a hypothetical patient with lower-limb loss receiving a first prosthesis and gait training in its use. During this early postoperative period, the delicate residual-limb tissues are still adapting to the stresses of the prosthetic socket [5,86-87]. Therefore, the practitioner wishes to carefully manage the amount of weight the patient bears on the prosthesis and the amount of time the patient uses 
the prosthesis daily so that the skin tissues can gradually grow to tolerate the stresses applied by the prosthesis. In the clinic, the practitioner affixes a load-based sensing unit to the prosthesis and then shows the patient how to incrementally load the prosthesis while using an assistive device. The practitioner instructs the patient to use the prosthesis daily and to monitor the loading daily using the Web-based notification system. Figure 4 shows this hypothetical patient's use of the prosthesis over the first week. The feedback the patient receives from the system can be used to encourage adherence to a clinical schedule that promotes wound healing, development of healthy tissues, and increased use of the prosthesis.

As the hypothetical patient is able to tolerate larger loads, a practitioner elects to monitor the patient's activity over subsequent weeks to ensure that progress is maintained and that no setbacks occur. Figure 5 shows the hypothetical patient's activity intensity over several months of rehabilitation. At this point in the rehabilitation process, the patient is able to tolerate increasingly longer and higher loads as the soft tissues adapt and the patient accommodates to use of the prosthesis. This activity information is useful for establishing a clinical visitation schedule or altering the training program, if insufficient progress is made.

Another related use of the therapeutic monitor is to document outcomes for the purposes of intervention assessment and justification. When applied this way, the

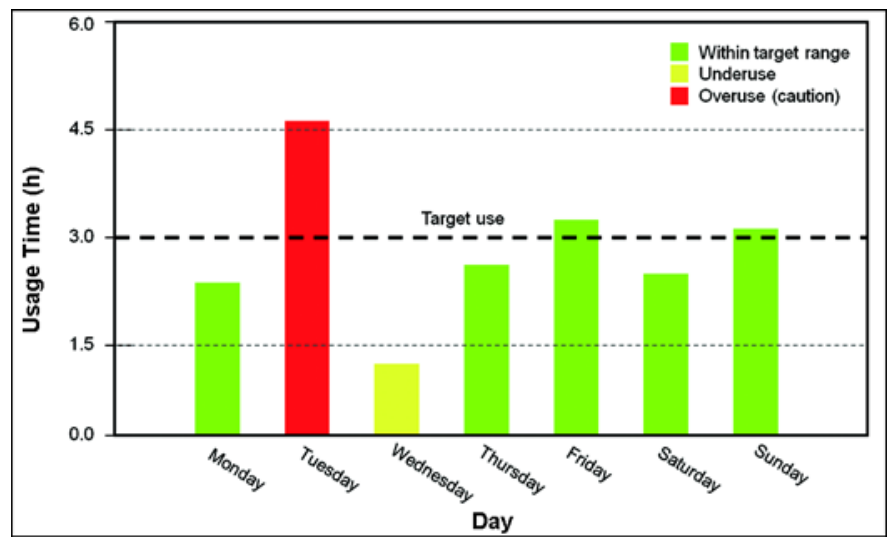

Figure 4.

Example of daily loading feedback provided to hypothetical patient who has received first prosthesis. Data shows daily performance (i.e., vertical loading) with respect to established clinical targets. Patient can use feedback to adjust loading patterns when he or she loads prosthesis too much or not enough.

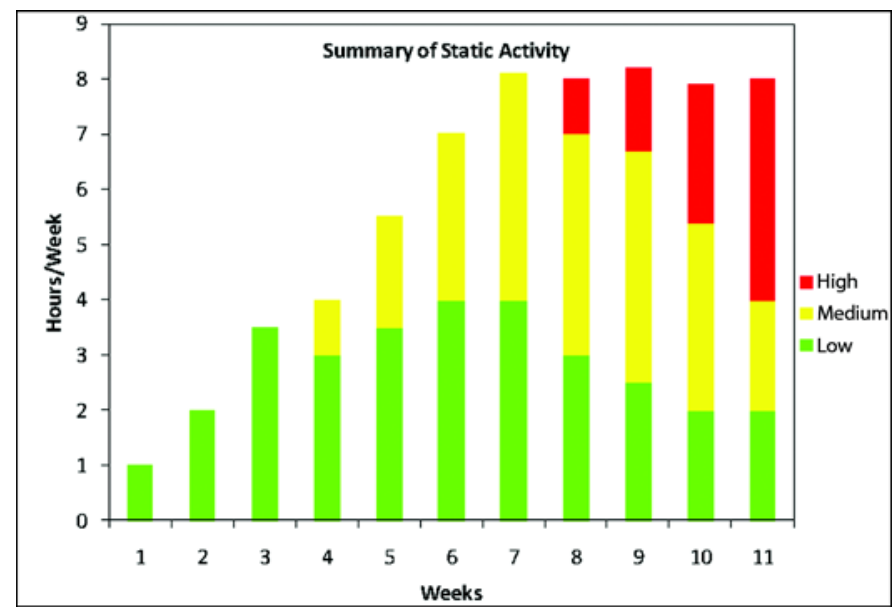

\section{Figure 5.}

Summary chart of hypothetical patient activity, highlighting time and intensity of loading. With this kind of information, practitioner can visualize patient's progress and observe unexpected changes in patterns that may require intervention.

system measures clinical outcomes before and after an intervention is provided to the patient. The management software is used to prepare a patient-specific outcomes report that shows the effect of the intervention. This report may be filed in the patient's medical file and used for later reference or sent to a reimbursement agency as justification of the intervention's effectiveness.

Given the relative paucity of research evidence related to many lower-limb prosthetic interventions, data collected using the therapeutic monitor is expected to facilitate development of information databases that illuminate differences among individuals with different clinical characteristics and among those interventions that most effectively address the limitations inherent to major limb amputation. Further, a database of this type of objective data will support development of evidence-based clinical practice guidelines and establish appropriate expectations for contemporary rehabilitation techniques.

\section{Diagnosis}

A second potential application for the proposed system is as a clinical diagnostic instrument. As before, the sensing unit is temporarily or permanently attached to the prosthesis. In its diagnostic configuration, the management software is used to instruct the system to collect and store the objective sensor data onboard the unit in resident memory. Manual or wireless download of the data directly 
to a personal computer is then initiated when the patient attends clinic. A software-based notification strategy is used to display the collected diagnostic data and allows the practitioner to extract features of clinical interest. This information is then compared to the patient's selfreport information in order to identify and remedy user problems such as skin breakdown, pain, or falls. The practitioner uses the obtained sensor data to determine whether the reported problems are the result of activity, intensity, frequency, suboptimal alignment, or suboptimal socket design. In this configuration, the system is used to quickly and efficiently diagnose and treat problems before they lead to more adverse issues.

In a diagnostic configuration, the sensor system may also be used in the clinic to assist in the selection of optimal prosthetic componentry. Consider use of the aforementioned kinetic sensing system for the purposes of prosthetic component selection. A hypothetical patient attends clinic and complains of discomfort and balance problems. The practitioner attaches the sensing system to the patient's prosthesis and requests that he or she stand quietly still for $30 \mathrm{~s}$ while the diagnostic monitor records data. The practitioner removes the monitor and downloads the data to a personal computer or wirelessly sends it to a personal computer. Experience with static standing in healthy amputees has prepared the practitioner to expect stable kinetic data like that shown in Figure 6(a). The hypothetical patient, however, presents with kinetic data like that shown in Figure 6(b), suggesting rapid weight shifts. Excessive weight shifting during everyday activity is indicative of balance problems ${ }^{*}$ and is a possible indicator of instability. The practitioner uses this knowledge and the data made available by the sensing system to initiate a conversation with the patient and to perform a physical evaluation. The results of this hypothetical patient interaction show that the patient exhibits poor sensation and proprioception, likely induced by sleeplessness and medications. The practitioner recommends exchanging the patient's existing multiaxial foot with a rigid, fixed ankle foot until the medical issues are resolved. To confirm the decision, the practitioner again attaches the sensor, asks the patient to stand, and records data. The data download, as shown in Figure 6(c), shows

\footnotetext{
*Sutter JD. Electronic “iShoe" aims to prevent falls [Internet]. CNN.com. 2010 Jul 1. Available from:

http://www.cnn.com/2010/TECH/03/03/ishoe.mit.award/index.html
}

(a)

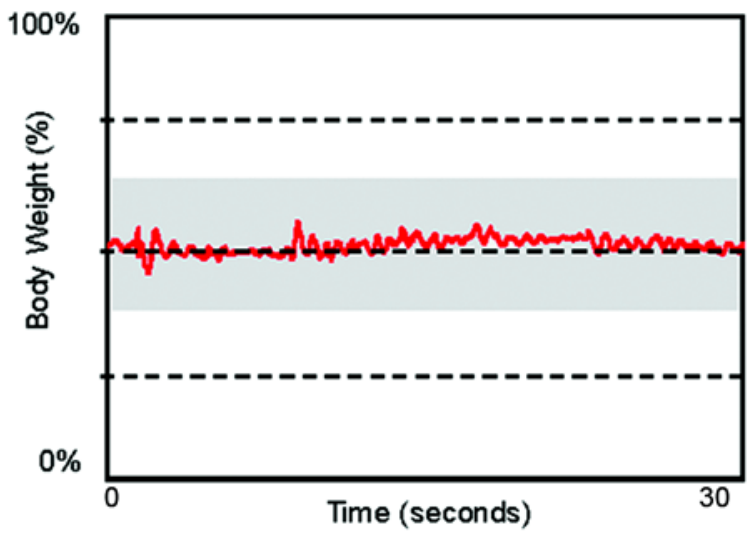

(b)

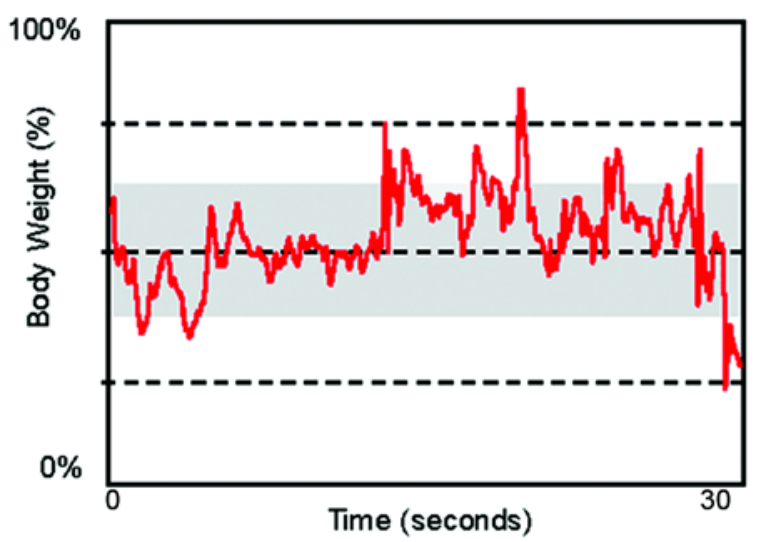

(c)

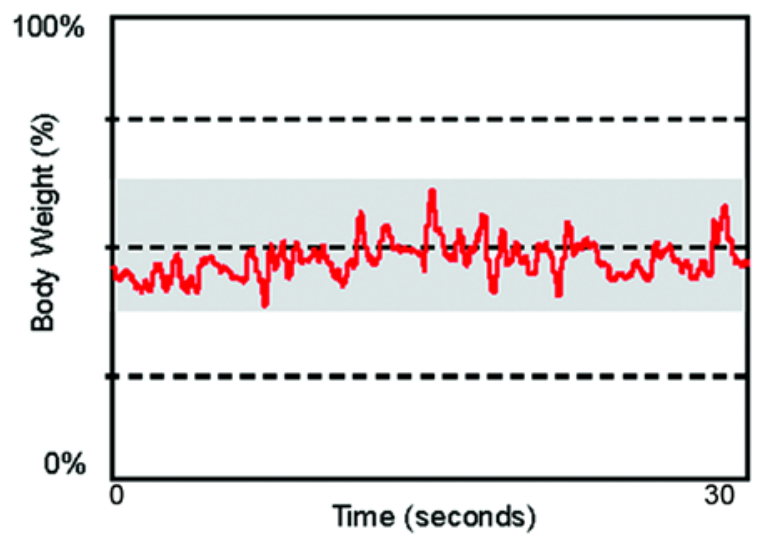

Figure 6.

Static stability for hypothetical patient, as indicated by relative loading of prosthesis during $30 \mathrm{~s}$ of quiet standing. Gray area represents suggested zone of stability for static standing. Sensor data are expected to help differentiate between patients and conditions, for example (a) healthy transtibial amputee, (b) patient that presents with poor proprioception and balance when wearing multi-axial foot, and (c) patient that presents with poor proprioception and balance after transition to solid-ankle foot. Pattern in (c) shows that patient is more stable wearing solidankle foot. Data were collected using piezoelectric force sensor positioned in prosthesis. 
that standing stability is markedly improved. The hypothetical patient is then referred to his or her managing physician to discuss the sleeplessness issues and return for another prosthetic evaluation in a week. As shown, the sensor system facilitates diagnostic skill, supports evidence-based practice, and improves the overall quality of care provided. Use of sensing technologies in this manner represents an unchartered area of research in prosthetics as well as in portable gait characterization of nonamputees [88].

\section{Prognosis}

A third potential application of the proposed system is as an autonomous prognostic monitor. In this configuration, the sensing unit is permanently integrated into the prosthesis and used to monitor the user's performance for signs of adverse behaviors (i.e., stumbles, excessive pistoning) that require the user and/or practitioner's attention. The practitioner configures the management software to provide active, perpetual feedback to the user through the desired mechanism (e.g., auditory, vibratory, or text message to the user's smartphone) and to send summary reports to the practitioner on a weekly basis. In the event that adverse condition predictors are detected, the system notifies the patient, thus allowing the user to change behavior or seek assistance before the adverse event, fall, or skin breakdown occurs. Similarly, summary reports sent to the practitioner can be used to ensure the user is safely using his or her prosthesis or to prompt a clinic visit in the event problems are detected. In this configuration, the sensor system serves as an "advanced warning system" that helps to reduce the likelihood of harm and the personal and economic outcomes associated with such injuries (i.e., hospitalization, prosthetic disuse, medical leave from work). Other quantitative measures may be useful; for example, sensors might measure limb-socket slip or excessive skin strains.

Consider the example of a hypothetical patient with a recent amputation, fitted with his or her first prosthesis. A prosthetic pylon with the integrated sensor system is affixed to the patient's temporary prosthetic socket. The sensor is a highly sensitive dynamic force sensor capable of measuring high-frequency fluctuations in force that occur when the residual limb slides relative to the liner or socket. During the initial visit, the practitioner adjusts the prosthetic socket until an acceptable fit is achieved. Using the management software, the practitioner sets the sensing unit to detect slip between the prosthetic socket and the residual limb. While with the patient, the practitioner adjusts the sensitivity of the slip monitor so that the system detects undesirable limb-socket displacements. The practitioner instructs the system to send weekly notifications of progress. After 1 week, the notification system relays a report (Figure 7) to the practitioner. As shown, the patient's activity has increased as he or she has grown accustomed to using the prosthesis. However, after several days of use, slip has started to regularly occur, likely due to reduced edema in the residual limb as the limb heals and accommodates to the mechanical stresses of the prosthetic socket. This result prompts the practitioner to contact the patient and schedule an appointment and adjust the prosthetic socket with pads so as to minimize slip and prevent soft tissue damage. As shown, the system helps the practitioner to provide timely intervention in order to prevent placing the patient at undue risk. This configuration presents a cost- and resource-efficient strategy for providing effective prosthetic care.

\section{INTEGRATING SENSING TECHNOLOGIES INTO CLINICAL PRACTICE}

The previous examples illustrate the potential for sensing and monitoring technologies to change how we

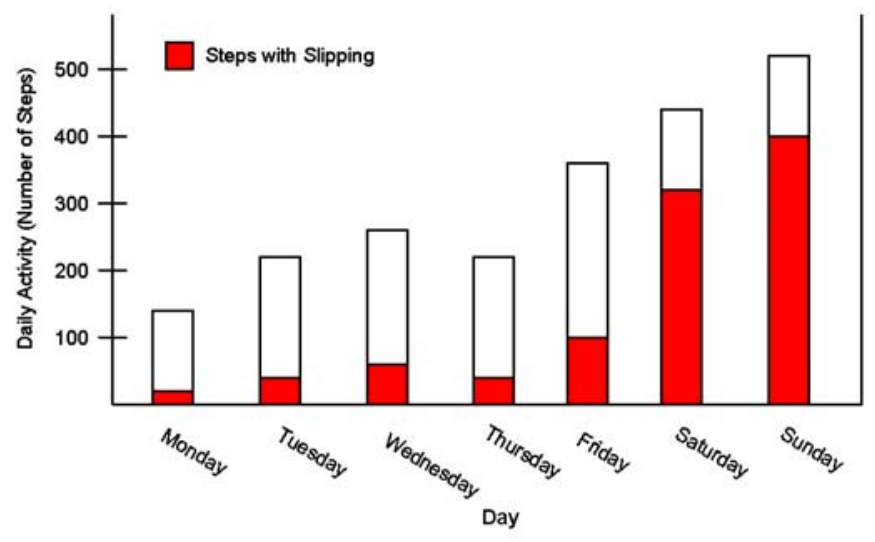

Figure 7.

Step activity and limb-socket slippage for hypothetical patient. Practitioner-generated report shows that after $5 \mathrm{~d}$ of use slip occurs regularly. This suggests that clinical intervention is necessary to avoid residual-limb tissue breakdown or falls due to poor suspension. 
approach and apply rehabilitation interventions. Physical and biological sensors can provide practitioners and patients with information that is objective, reliable, and presently unavailable to them. Notification strategies can communicate the obtained information more rapidly and efficiently than is possible with routine office visits. Management software can customize the type and timing of information so that it meets the needs of the recipients. Integration of these systems into lower-limb prostheses can enrich a practitioner's toolkit and facilitate provision of individualized, efficient, and evidence-based care for persons with lower-limb loss.

It is important to acknowledge that sensing and monitoring technologies should not be viewed as a strategy for replacing the experience of qualified practitioners or eliminating clinician-patient interactions. Attempting to substitute clinicians' experience and/or judgment with these nascent technologies may worsen, rather than enhance, clinical care. Instead, sensing systems should be envisioned as tools to complement or extend practitioners' existing skills and knowledge. Future efforts should therefore explore how best to apply these systems so as to augment traditional methods of care.

We recognize that challenges to incorporating sensing technologies into routine clinical practice remain. For devices such as those exemplified previously to be successful, they must avoid adding to the burden of a clinical provider. Practitioners working in a busy clinical environment will have limited tolerance for devices that are difficult to integrate into a prosthesis, software that is cumbersome to use, or data that is challenging to interpret. Integration of devices into clinical practice must also be cost-effective. The additional time and expense associated with use of these technologies must be offset by improvements in the quality of care (e.g., selection of optimal componentry, shorter rehabilitation period, and/ or more reliable documentation) or an increased efficiency of healthcare resources (e.g., time required to diagnose problems, frequency of patient visits, and/or reduced occurrence of adverse events).

Lastly, monitoring of prosthetic users by practitioners and transmission of patient data are certain to raise a variety of ethical concerns. Although an in-depth review of ethical issues related to health monitoring in prosthetic applications is beyond the scope of this review, discussions related to responsibility of action, liability, compliance, social stigmas, ownership, data integrity, and privacy of health information in other healthcare fields are common [89-93]. Zwijsen and colleagues recently conducted a thorough review and discussion of ethical issues related to monitoring technologies [90]. They noted three primary themes related to monitoring elderly adults that would likely also apply to prosthesis users. Themes included the personal living environment (e.g., issues of privacy, autonomy, and obtrusiveness), the outside world (e.g., issues of stigma and reduced human contact), and design and application of the device (e.g., issues of technology personalization, affordability, and safety). Other concerns, such as a practitioners' responsibility for monitoring and reporting negative outcomes, misuse or misinterpretation of collected information by third parties, and inclusion of monitored data in patients' permanent medical record were not identified in that review, but have been raised elsewhere [93]. Consideration and resolution of these issues may be warranted before sensing and monitoring technologies are universally adopted for prosthetic users. Once ethical concerns are addressed, sensing and monitoring technologies would appear to have enormous potential for enhancing prosthetics practice and improving the lives of persons with lower-limb loss.

\section{CONCLUSIONS}

Rehabilitation of persons with lower-limb loss is enhanced with knowledge of patients' functioning and health. Advances in sensing and monitoring technologies have made obtaining such information directly from prosthetic patients possible across a variety of settings (e.g., hospitals, prosthetic clinics, homes, and communities). Sensors can acquire useful and meaningful health information perpetually and remotely, but often require patients to remain compliant with application and wear recommendations. Integrating sensors into prosthetic limbs overcomes many limitations to use of stand-alone sensor devices for health monitoring. However, sensing technologies have yet to be integrated into routine clinical practices or used regularly to enhance the quality of care provided to persons with limb loss. However, a growing prevalence of available sensors and emergence of novel technologies will serve to promote these and related health applications.

Here, a multidimensional model of rehabilitation that embraces use of sensing and monitoring technologies for communicating information between (or among) prosthetic 
devices, patients, and their healthcare providers is proposed. Several hypothetical clinical situations are presented to illustrate how information from physical and biological sensors could be used to promote successful outcomes for prosthetic patients. Although challenges to development of efficient, cost-effective sensor systems for prosthetic applications remain, they can be addressed. Thoughtfully developing and integrating sensor systems into clinical practice has the potential to enhance the quality of care provided to persons with limb loss and to promote prosthetic users' function, health, and quality of life.

\section{ACKNOWLEDGMENTS}

\author{
Author Contributions: \\ Review concept and design: B. J. Hafner, J. E. Sanders. \\ Drafting of manuscript: B. J. Hafner, J. E. Sanders. \\ Critical revision of manuscript for important intellectual content: \\ B. J. Hafner, J. E. Sanders.
}

Financial Disclosures: The authors have declared that no competing interests exist.

Funding/Support: Funding for Drs. Hafner and Sanders was provided in part by the National Institutes of Health (R01HD069387) and the Department of Defense (W81XWH-10-1-1035).

\section{REFERENCES}

1. Ziegler-Graham K, MacKenzie EJ, Ephraim PL, Travison TG, Brookmeyer R. Estimating the prevalence of limb loss in the United States: 2005 to 2050. Arch Phys Med Rehabil. 2008;89(3):422-29. [PMID:18295618] http://dx.doi.org/10.1016/j.apmr.2007.11.005

2. van Velzen JM, van Bennekom CA, Polomski W, Slootman JR, van der Woude LH, Houdijk H. Physical capacity and walking ability after lower limb amputation: A systematic review. Clin Rehabil. 2006;20(11):999-1016. [PMID:17065543] http://dx.doi.org/10.1177/0269215506070700

3. Schoppen T, Boonstra A, Groothoff JW, de Vries J, Göeken LN, Eisma WH. Physical, mental, and social predictors of functional outcome in unilateral lower-limb amputees. Arch Phys Med Rehabil. 2003;84(6):803-11.

[PMID:12808530]

http://dx.doi.org/10.1016/S0003-9993(02)04952-3

4. Pohjolainen T, Alaranta H, Kärkkäinen M. Prosthetic use and functional and social outcome following major lower limb amputation. Prosthet Orthot Int. 1990;14(2):75-79. [PMID:2235304]
5. Post-operative management of the lower extremity amputee. Chicago (IL): American Academy of Orthotists and Prosthetists (AAOP); 2004.

6. Vrieling AH, van Keeken HG, Schoppen T, Otten E, Halbertsma JP, Hof AL, Postema K. Uphill and downhill walking in unilateral lower limb amputees. Gait Posture. 2008;28(2): 235-42. [PMID:18242995] http://dx.doi.org/10.1016/j.gaitpost.2007.12.006

7. Miller WC, Deathe AB. A prospective study examining balance confidence among individuals with lower limb amputation. Disabil Rehabil. 2004;26(14-15):875-81. [PMID:15497916] http://dx.doi.org/10.1080/09638280410001708887

8. Miller WC, Deathe AB, Speechley M. Psychometric properties of the Activities-Specific Balance Confidence Scale among individuals with a lower-limb amputation. Arch Phys Med Rehabil. 2003;84(5):656-61. [PMID:12736877] http://dx.doi.org/10.1016/S0003-9993(02)04807-4

9. Buckley JG, O’Driscoll D, Bennett SJ. Postural sway and active balance performance in highly active lower-limb amputees. Am J Phys Med Rehabil. 2002;81(1):13-20. [PMID:11807327] http://dx.doi.org/10.1097/00002060-200201000-00004

10. Miller WC, Speechley M, Deathe B. The prevalence and risk factors of falling and fear of falling among lower extremity amputees. Arch Phys Med Rehabil. 2001;82(8): 1031-37. [PMID:11494181] http://dx.doi.org/10.1053/apmr.2001.24295

11. Genin JJ, Bastien GJ, Franck B, Detrembleur C, Willems PA. Effect of speed on the energy cost of walking in unilateral traumatic lower limb amputees. Eur J Appl Physiol. 2008;103(6):655-63. [PMID:18478251] http://dx.doi.org/10.1007/s00421-008-0764-0

12. Chin T, Sawamura S, Shiba R, Oyabu H, Nagakura Y, Takase I, Machida K, Nakagawa A. Effect of an Intelligent Prosthesis (IP) on the walking ability of young transfemoral amputees: Comparison of IP users with able-bodied people. Am J Phys Med Rehabil. 2003;82(6):447-51. [PMID:12820787] http://dx.doi.org/10.1097/01.PHM.0000069191.20125.38

13. Waters RL, Mulroy S. The energy expenditure of normal and pathologic gait. Gait Posture. 1999;9(3):207-31. [PMID:10575082] http://dx.doi.org/10.1016/S0966-6362(99)00009-0

14. Donker SF, Beek PJ. Interlimb coordination in prosthetic walking: Effects of asymmetry and walking velocity. Acta Psychol (Amst). 2002;110(2-3):265-88. [PMID:12102109] http://dx.doi.org/10.1016/S0001-6918(02)00037-9

15. Jaegers SM, Arendzen JH, de Jongh HJ. Prosthetic gait of unilateral transfemoral amputees: A kinematic study. Arch 
Phys Med Rehabil. 1995;76(8):736-43. [PMID:7632129] http://dx.doi.org/10.1016/S0003-9993(95)80528-1

16. Hof AL, van Bockel RM, Schoppen T, Postema K. Control of lateral balance in walking. Experimental findings in normal subjects and above-knee amputees. Gait Posture. 2007; 25(2):250-58. [PMID:16740390] http://dx.doi.org/10.1016/j.gaitpost.2006.04.013

17. Nolan L, Wit A, Dudziñski K, Lees A, Lake M, Wychowañski M. Adjustments in gait symmetry with walking speed in trans-femoral and trans-tibial amputees. Gait Posture. 2003;17(2):142-51. [PMID:12633775] http://dx.doi.org/10.1016/S0966-6362(02)00066-8

18. Miller WC, Deathe AB, Speechley M, Koval J. The influence of falling, fear of falling, and balance confidence on prosthetic mobility and social activity among individuals with a lower extremity amputation. Arch Phys Med Rehabil. 2001;82(9):1238-44. [PMID:11552197] http://dx.doi.org/10.1053/apmr.2001.25079

19. Stepien JM, Cavenett S, Taylor L, Crotty M. Activity levels among lower-limb amputees: Self-report versus step activity monitor. Arch Phys Med Rehabil. 2007;88(7):896-900. [PMID:17601471] http://dx.doi.org/10.1016/j.apmr.2007.03.016

20. Holden J, Fernie G. Minimal walking levels for amputees living at home. Physiother Can. 1983;35(6):317-20.

21. Holden JM, Fernie GR. Extent of artificial limb use following rehabilitation. J Orthop Res. 1987;5(4):562-68.

[PMID:3681530] http://dx.doi.org/10.1002/jor.1100050411

22. Ramstrand N, Nilsson KA. A comparison of foot placement strategies of transtibial amputees and able-bodied subjects during stair ambulation. Prosthet Orthot Int. 2009; 33(4):348-55. [PMID:19961296] http://dx.doi.org/10.3109/03093640903074891

23. Vrieling AH, van Keeken HG, Schoppen T, Otten E, Halbertsma JP, Hof AL, Postema K. Obstacle crossing in lower limb amputees. Gait Posture. 2007;26(4):587-94. [PMID:17275306] http://dx.doi.org/10.1016/j.gaitpost.2006.12.007

24. Jones SF, Twigg PC, Scally AJ, Buckley JG. The mechanics of landing when stepping down in unilateral lower-limb amputees. Clin Biomech (Bristol, Avon). 2006;21(2):184-93. [PMID:16274904] http://dx.doi.org/10.1016/j.clinbiomech.2005.09.015

25. Pezzin LE, Dillingham TR, MacKenzie EJ. Rehabilitation and the long-term outcomes of persons with trauma-related amputations. Arch Phys Med Rehabil. 2000;81(3):292-300. [PMID:10724073] http://dx.doi.org/10.1016/S0003-9993(00)90074-1

26. Meulenbelt HE, Geertzen JH, Jonkman MF, Dijkstra PU. Determinants of skin problems of the stump in lower-limb amputees. Arch Phys Med Rehabil. 2009;90(1):74-81.

\section{[PMID:19154832]}

http://dx.doi.org/10.1016/j.apmr.2008.07.015

27. Dudek NL, Marks MB, Marshall SC, Chardon JP. Dermatologic conditions associated with use of a lower-extremity prosthesis. Arch Phys Med Rehabil. 2005;86(4):659-63. [PMID:15827914] http://dx.doi.org/10.1016/j.apmr.2004.09.003

28. Struyf PA, van Heugten CM, Hitters MW, Smeets RJ. The prevalence of osteoarthritis of the intact hip and knee among traumatic leg amputees. Arch Phys Med Rehabil. 2009;90(3):440-46. [PMID:19254609]

http://dx.doi.org/10.1016/j.apmr.2008.08.220

29. Robbins CB, Vreeman DJ, Sothmann MS, Wilson SL, Oldridge NB. A review of the long-term health outcomes associated with war-related amputation. Mil Med. 2009;174(6): 588-92. [PMID:19585770] http://dx.doi.org/10.7205/MILMED-D-00-0608

30. Norvell DC, Czerniecki JM, Reiber GE, Maynard C, Pecoraro JA, Weiss NS. The prevalence of knee pain and symptomatic knee osteoarthritis among veteran traumatic amputees and nonamputees. Arch Phys Med Rehabil. 2005; 86(3):487-93. [PMID:15759233] http://dx.doi.org/10.1016/j.apmr.2004.04.034

31. Raichle KA, Hanley MA, Molton I, Kadel NJ, Campbell K, Phelps E, Ehde D, Smith DG. Prosthesis use in persons with lower- and upper-limb amputation. J Rehabil Res Dev. 2008;45(7):961-72. [PMID:19165686] http://dx.doi.org/10.1682/JRRD.2007.09.0151

32. Ephraim PL, Wegener ST, MacKenzie EJ, Dillingham TR, Pezzin LE. Phantom pain, residual limb pain, and back pain in amputees: Results of a national survey. Arch Phys Med Rehabil. 2005;86(10):1910-19. [PMID:16213230] http://dx.doi.org/10.1016/j.apmr.2005.03.031

33. Ehde DM, Czerniecki JM, Smith DG, Campbell KM, Edwards WT, Jensen MP, Robinson LR. Chronic phantom sensations, phantom pain, residual limb pain, and other regional pain after lower limb amputation. Arch Phys Med Rehabil. 2000;81(8):1039-44. [PMID:10943752] http://dx.doi.org/10.1053/apmr.2000.7583

34. Smith DG, Ehde DM, Legro MW, Reiber GE, del Aguila M, Boone DA. Phantom limb, residual limb, and back pain after lower extremity amputations. Clin Orthop Relat Res. 1999;(361):29-38. [PMID:10212593] http://dx.doi.org/10.1097/00003086-199904000-00005

35. Dougherty PJ. Long-term follow-up of unilateral transfemoral amputees from the Vietnam war. J Trauma. 2003;54(4): 718-23. [PMID:12707534] http://dx.doi.org/10.1097/01.TA.0000046260.16866.A9

36. Hagberg K, Brånemark R. Consequences of non-vascular trans-femoral amputation: A survey of quality of life, prosthetic use and problems. Prosthet Orthot Int. 2001;25(3): 
186-94. [PMID:11860092]

http://dx.doi.org/10.1080/03093640108726601

37. Legro MW, Reiber G, del Aguila M, Ajax MJ, Boone DA, Larsen JA, Smith DG, Sangeorzan B. Issues of importance reported by persons with lower limb amputations and prostheses. J Rehabil Res Dev. 1999;36(3):155-63.

[PMID:10659798]

38. Smith DG, Horn P, Malchow D, Boone DA, Reiber GE, Hansen ST Jr. Prosthetic history, prosthetic charges, and functional outcome of the isolated, traumatic below-knee amputee. J Trauma. 1995;38(1):44-47. [PMID:7745656] http://dx.doi.org/10.1097/00005373-199501000-00013

39. Ware JE Jr, Sherbourne CD. The MOS 36-item short-form health survey (SF-36). I. Conceptual framework and item selection. Med Care. 1992;30(6):473-83. [PMID:1593914] http://dx.doi.org/10.1097/00005650-199206000-00002

40. Sullivan M, Karlsson J, Ware J. SF-36 Hälsoenkäf. Svensk Manual och tolkingsguide (Swedish manual and interpretation guide). Gothenburg (Sweden): Sahlgrenska University Hospital; 1994. Swedish.

41. Mayfield JA, Reiber GE, Sanders LJ, Janisse D, Pogach LM. Preventive foot care in people with diabetes. Diabetes Care. 1998;21(12):2161-77. [PMID:9839111]

http://dx.doi.org/10.2337/diacare.21.12.2161

42. Paulhus DL, Vazire S. The self-report method. In: Robins RW, Fraley RC, Krueger RF, editors. Handbook of research methods in personality psychology. London: The Guilford Press; 2007. p. 224-39.

43. Gorin AA, Stone AA. Recall biases and cognitive errors in retrospective self-reports: A call for momentary assessments. In: Baum A, Revenson T, Singer J, editors. Handbook of health psychology. Mahwah (NJ): Lawrence Erlbaum; 2001. p. 405-13.

44. Paulhus DP. Measurement and control of response bias. In: Robinson JP, Shaver PR, Wrightsman LS, editors. Measures of personality and social psychological attitudes. San Diego (CA): Academic Press; 1991. p. 17-59.

45. John OP, Robins RW. Accuracy and bias in self-perception: Individual differences in self-enhancement and the role of narcissism. J Pers Soc Psychol. 1994;66(1):206-19.

[PMID:8126650]

http://dx.doi.org/10.1037/0022-3514.66.1.206

46. Moskowitz DS. Comparison of self-reports, reports by knowledgeable informants, and behavioral observation data. J Pers. 1986;54:294-317.

http://dx.doi.org/10.1111/j.1467-6494.1986.tb00396.x

47. S Roriz-Filho J, Sá-Roriz TM, Rosset I, Camozzato AL, Santos AC, Chaves ML, Moriguti JC, Roriz-Cruz M. (Pre)diabetes, brain aging, and cognition. Biochim Biophys Acta. 2009;1792(5):432-43. [PMID:19135149] http://dx.doi.org/10.1016/j.bbadis.2008.12.003
48. Phillips NA, Mate-Kole CC, Kirby RL. Neuropsychological function in peripheral vascular disease amputee patients. Arch Phys Med Rehabil. 1993;74(12):1309-14. [PMID:8259898]

49. Sackett DL, Rosenberg WM, Gray JA, Haynes RB, Richardson WS. Evidence based medicine: What it is and what it isn’t. BMJ. 1996;312(7023):71-72. [PMID:8555924] http://dx.doi.org/10.1136/bmj.312.7023.71

50. Finch E, Brooks D, Stratford PW, Mayo NE. Physical rehabilitation outcome measures. 2nd ed. Baltimore (MD): Lippincott Williams and Wilkins; 2002.

51. Khaylis A, Yiaslas T, Bergstrom J, Gore-Felton C. A review of efficacious technology-based weight-loss interventions: Five key components. Telemed J E Health. 2010; 16(9):931-38. [PMID:21091286] http://dx.doi.org/10.1089/tmj.2010.0065

52. Siriwardena LS, Wickramasinghe WA, Perera KL, Marasinghe RB, Katulanda P, Hewapathirana RJ. A review of telemedicine interventions in diabetes care. J Telemed Telecare. 2012;18(3):164-68. [PMID:22362832] http://dx.doi.org/10.1258/jtt.2012.SFT110

53. Wainwright $\mathrm{C}$, Wootton R. A review of telemedicine and asthma. Dis Manag Health Outcomes. 2003;11(9):557-63. http://dx.doi.org/10.2165/00115677-200311090-00003

54. Radhakrishnan K, Jacelon C. Impact of telehealth on patient self-management of heart failure: A review of literature. J Cardiovasc Nurs. 2012;27(1):33-43. [PMID:21558862] http://dx.doi.org/10.1097/JCN.0b013e318216a6e9

55. Klersy C, De Silvestri A, Gabutti G, Raisaro A, Curti M, Regoli F, Auricchio A. Economic impact of remote patient monitoring: An integrated economic model derived from a meta-analysis of randomized controlled trials in heart failure. Eur J Heart Fail. 2011;13(4):450-59. [PMID:21193439] http://dx.doi.org/10.1093/eurjhf/hfq232

56. Alwan M, Sifferlin EB, Turner B, Kell S, Brower P, Mack DC, Dalal S, Felder RA. Impact of passive health status monitoring to care providers and payers in assisted living. Telemed J E Health. 2007;13(3):279-85.

[PMID:17603830] http://dx.doi.org/10.1089/tmj.2006.0056

57. Johnston B, Wheeler L, Deuser J, Sousa KH. Outcomes of the Kaiser Permanente Tele-Home Health Research Project. Arch Fam Med. 2000;9(1):40-45. [PMID:10664641] http://dx.doi.org/10.1001/archfami.9.1.40

58. Dittmar A, Axisa F, Delhomme G, Gehin C. New concepts and technologies in home care and ambulatory monitoring. Stud Health Technol Inform. 2004;108:9-35. [PMID:15718626]

59. Gailey RS, Nash MS, Atchley TA, Zilmer RM, Moline-Little GR, Morris-Cresswell N, Siebert LI. The effects of prosthesis 
mass on metabolic cost of ambulation in non-vascular trans-tibial amputees. Prosthet Orthot Int. 1997;21(1):9-16. [PMID:9141121]

60. Czerniecki JM, Gitter A, Weaver K. Effect of alterations in prosthetic shank mass on the metabolic costs of ambulation in above-knee amputees. Am J Phys Med Rehabil. 1994;73(5):348-52. [PMID:7917165] http://dx.doi.org/10.1097/00002060-199409000-00008

61. Gitter A, Czerniecki J, Meinders M. Effect of prosthetic mass on swing phase work during above-knee amputee ambulation. Am J Phys Med Rehabil. 1997;76(2):114-21. [PMID:9129517] http://dx.doi.org/10.1097/00002060-199703000-00006

62. Godfrey A, Conway R, Meagher D, O’Laighin G. Direct measurement of human movement by accelerometry. Med Eng Phys. 2008;30(10):1364-86. [PMID:18996729] http://dx.doi.org/10.1016/j.medengphy.2008.09.005

63. Mathie MJ, Coster AC, Lovell NH, Celler BG. Accelerometry: Providing an integrated, practical method for longterm, ambulatory monitoring of human movement. Physiol Meas. 2004;25(2):R1-20. [PMID:15132305] http://dx.doi.org/10.1088/0967-3334/25/2/R01

64. Ramstrand N, Nilsson KA. Validation of a patient activity monitor to quantify ambulatory activity in an amputee population. Prosthet Orthot Int. 2007;31(2):157-66. [PMID:17520493] http://dx.doi.org/10.1080/03093640600988617

65. Coleman KL, Smith DG, Boone DA, Joseph AW, del Aguila MA. Step activity monitor: Long-term, continuous recording of ambulatory function. J Rehabil Res Dev. 1999;36(1):8-18. [PMID:10659890]

66. Yang C-C, Hsu Y-L. A review of accelerometry-based wearable motion detectors for physical activity monitoring. Sensors (Basel). 2010;10(8):7772-88. [PMID:22163626] http://dx.doi.org/10.3390/s100807772

67. Hafner BJ, Willingham LL, Buell NC, Allyn KJ, Smith DG. Evaluation of function, performance, and preference as transfemoral amputees transition from mechanical to microprocessor control of the prosthetic knee. Arch Phys Med Rehabil. 2007;88(2):207-17. [PMID:17270519] http://dx.doi.org/10.1016/j.apmr.2006.10.030

68. Klute GK, Berge JS, Orendurff MS, Williams RM, Czerniecki JM. Prosthetic intervention effects on activity of lower-extremity amputees. Arch Phys Med Rehabil. 2006;87(5):717-22. [PMID:16635636] http://dx.doi.org/10.1016/j.apmr.2006.02.007

69. Godfrey A, Bourke AK, Olaighin GM, van de Ven P, Nelson J. Activity classification using a single chest mounted tri-axial accelerometer. Med Eng Phys. 2011;33(9):1127-35. [PMID:21636308] http://dx.doi.org/10.1016/j.medengphy.2011.05.002
70. Curone D, Bertolotti GM, Cristiani A, Secco EL, Magenes G. A real-time and self-calibrating algorithm based on triaxial accelerometer signals for the detection of human posture and activity. IEEE Trans Inf Technol Biomed. 2010; 14(4):1098-1105. [PMID:20483689] http://dx.doi.org/10.1109/TITB.2010.2050696

71. Redfield MT, Cagle JC, Hafner BJ, Sanders JE. Classifying prosthetic use via accelerometry in persons with transtibial amputations. J Rehabil Res Dev. 2014;50(9):1201-12. [PMID:24458961]

72. Frossard L, Beck J, Dillon M, Evans J. Development and preliminary testing of a device for the direct measurement of forces and moments in the prosthetic limb of transfemoral amputees during activities of daily living. J Prosthet Orthot. 2003;15(4):135-42. http://dx.doi.org/10.1097/00008526-200310000-00005

73. Sanders JE, Miller RA, Berglund DN, Zachariah SG. A modular six-directional force sensor for prosthetic assessment: A technical note. J Rehabil Res Dev. 1997;34(2): 195-202. [PMID:9108346]

74. Winarski DJ, Pearson JR. Least-squares matrix correlations between stump stresses and prosthesis loads for belowknee amputees. J Biomech Eng. 1987;109(3):238-46. [PMID:3657112] http://dx.doi.org/10.1115/1.3138675

75. Berme N, Lawes P, Solomonidis S, Paul JP. A shorter pylon transducer for measurement of prosthetic forces and moments during amputee gait. Eng Med. 1975;4:6-8. http://dx.doi.org/10.1243/EMED JOUR 197500403202

76. Sanders JE, Zachariah SG, Jacobsen AK, Fergason JR. Changes in interface pressures and shear stresses over time on trans-tibial amputee subjects ambulating with prosthetic limbs: Comparison of diurnal and six-month differences. J Biomech. 2005;38(8):1566-73. [PMID:15958212] http://dx.doi.org/10.1016/j.jbiomech.2004.08.008

77. Sanders JE, Daly CH. Measurement of stresses in three orthogonal directions at the residual limb/prosthetic socket interface. IEEE Trans Rehabil Eng. 1993;1:79-85. http://dx.doi.org/10.1109/86.242421

78. Lumelsky V, Shur MS, Wagner S, editors. Sensitive skin: Selected topics in electronics and systems, Volume 18. Singapore: World Scientific Pub Co; 2000.

79. Rowe GI, Mamishev AV. Simulation of a sensor array for multi-parameter measurements at the prosthetic limb interface. SPIE 9th Annual International Symposium on NDE for Health Monitoring and Diagnostics; 2004 Mar 14-18; San Diego, CA. Bellingham (WA): SPIE; 2000. p. 493-500.

80. Valdastri P, Roccella S, Beccai L, Cattin E, Menciassi A, Carrozza MC, Dario P. Characterization of a novel hybrid silicon three-axial force sensor. Sens Actuators A Phys. 2005;123-24:249-57. http://dx.doi.org/10.1016/j.sna.2005.01.006 
81. Cutkosky MR, Howe RD, Provancher WR. Force and tactile sensors. Siciliano B, Khatib O, editors. Springer handbook of robotics. New York (NY): Springer; 2008.

82. Huang Y-M, Tsai N-C, Lai J-Y. Development of tactile sensors for simultaneous detection of normal and shear stresses. Sens Actuators A Phys. 2010;159:189-95. http://dx.doi.org/10.1016/j.sna.2010.03.032

83. Missinne J, Bosman E, Van Hoe B, Van Steenberge G, Van Daele P, Vanfleteren J. Embedded flexible optical shear sensor. Proceedings of 2010 IEEE Sensors; 2010 Nov 1-4; Kona, HI. Piscataway (NJ): IEEE; 2010. p. 987-90.

84. Lincoln LS, Quigley M, Rohrer B, Salisbury C, Wheeler J. An optical 3D force sensor for biomedical devices. Fourth IEEE RAS/EMBS International Conference on Biomedical Robotics and Biomechatronics (BioRob 2012); 2012 Jun 24-27; Rome, Italy. Piscataway (NJ): IEEE; 2012. p. 15001505.

85. Tudor-Locke C, Lutes L. Why do pedometers work?: A reflection upon the factors related to successfully increasing physical activity. Sports Med. 2009;39(12):981-93. [PMID:19902981] http://dx.doi.org/10.2165/11319600-000000000-00000

86. Sanders JE, Goldstein BS, Leotta DF. Skin response to mechanical stress: Adaptation rather than breakdown-A review of the literature. J Rehabil Res Dev. 1995;32(3): 214-26. [PMID:8592293]

87. Carlson JM. Functional limitations from pain caused by repetitive loading on the skin: A review and discussion for practitioners, with new data for limiting friction loads. J Prosthet Orthot. 2006;18(4):93-103. http://dx.doi.org/10.1097/00008526-200610000-00002

88. Kavanagh JJ, Menz HB. Accelerometry: A technique for quantifying movement patterns during walking. Gait Posture. 2008;28(1):1-15. [PMID:18178436] http://dx.doi.org/10.1016/j.gaitpost.2007.10.010

89. Al Ameen M, Liu J, Kwak K. Security and privacy issues in wireless sensor networks for healthcare applications. J Med Syst. 2012;36(1):93-101. [PMID:20703745] http://dx.doi.org/10.1007/s10916-010-9449-4
90. Zwijsen SA, Niemeijer AR, Hertogh CM. Ethics of using assistive technology in the care for community-dwelling elderly people: An overview of the literature. Aging Ment Health. 2011;15(4):419-27. [PMID:21500008] http://dx.doi.org/10.1080/13607863.2010.543662

91. Kang HG, Mahoney DF, Hoenig H, Hirth VA, Bonato P, Hajjar I, Lipsitz LA; Center for Integration of Medicine and Innovative Technology Working Group on Advanced Approaches to Physiologic Monitoring for the Aged. In situ monitoring of health in older adults: Technologies and issues. J Am Geriatr Soc. 2010;58(8):1579-86.

[PMID:20646105] http://dx.doi.org/10.1111/j.1532-5415.2010.02959.x

92. Pharow P, Blobel B. Mobile health requires mobile security: challenges, solutions, and standardization. Stud Health Technol Inform. 2008;136:697-702. [PMID:18487813]

93. Rigby M. Applying emergent ubiquitous technologies in health: The need to respond to new challenges of opportunity, expectation, and responsibility. Int J Med Inform. 2007;76(Suppl 3):S349-52. [PMID:17434338] http://dx.doi.org/10.1016/j.ijmedinf.2007.03.002

Submitted for publication January 27, 2013. Accepted in revised form July 9, 2013.

This article and any supplemental material should be cited as follows:

Hafner BJ, Sanders JE. Considerations for development of sensing and monitoring tools to facilitate treatment and care of persons with lower-limb loss: A review. J Rehabil Res Dev. 2014:51(1):1-14.

http://dx.doi.org/10.1682/JRRD.2013.01.0024

ResearcherID/ORCID: Joan E. Sanders, PhD: E-82042011; Brian J. Hafner, PhD: M-6322-2013

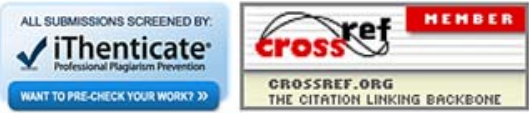

